\title{
APLICAÇÃO DO CONTROLE DA QUALIDADE NO SETOR DE HORTIFRÚTI DE UM SUPERMERCADO VISANDO A REDUÇÃO DE PERDAS
}

\author{
Beatriz Martins Pereira, Graciele Priscila de Oliveira Bravin, Andréia de Menezes Olivo \\ Universidade do Oeste Paulista - UNOESTE, Faculdade de Engenharia Conselheiro Algacyr Munhoz Maéder, Curso de \\ Engenharia de Produção, Presidente Prudente, SP. E-mail: bia martins260597@hotmail.com.
}

\begin{abstract}
RESUMO
O presente trabalho tem como finalidade aplicar as ferramentas da qualidade no setor de hortifrúti de uma rede de supermercado varejista, a fim de reduzir as perdas e minimizar custos. Foi realizado um levantamento das perdas do setor, aplicando as ferramentas da qualidade para diagnóstico da origem do problema e tomada de decisão, e por fim realizou-se uma análise dos dados com o intuito de propor a metodologia adequada para a solução do problema. A pesquisa foi de natureza quali-quantitativa com caráter exploratório tendo como método de investigação o estudo de caso. A pesquisa bibliográfica, pesquisa documental e observação foram utilizadas como instrumentos da coleta de dados. Os resultados obtidos nos mostraram que os fatores que provocam ou auxiliam o aumento das quebras são o excesso de umidade relativa do ar, transporte, manuseio incorreto ou excessivo e acondicionamento não adequado.

Palavras-chave: Controle. Ciclo PDCA. Qualidade. Ferramentas da Qualidade. Minimização de custos
\end{abstract}

\section{QUALITY OF THE CONTROL APPLICATION ON THE FRUIT AND VEGETABLE SECTOR IN SUPERMARKET FOR THE REDUCTION OF LOSSES}

\begin{abstract}
This present work aims to apply the quality tools in the fruit and vegetables sector of a retail supermarket chain, in order to reduce losses and minimize costs. It was carried out a survey of the losses of the sector, applying the quality tools to diagnose the origin of the problem and decision making, and finally an analysis of the data was carried out with the purpose of proposing the appropriate methodology for the solution of the problem. The research was of qualitativequantitative nature with exploratory character having as investigation method the case study. Bibliographic research, documentary research and observation were used as tools for data collection. The results obtained showed that the factors that provoke or help increase the breaks are the excess of relative humidity of the air, transport, incorrect or excessive handling and inadequate packing.
\end{abstract}

Keywords: Control. PDCA cycle. Quality. Quality Tools. Costminimization. 


\section{INTRODUÇÃO}

O varejo brasileiro em 2014 perdeu em média 2,89\% de seu faturamento líquido em virtude de furtos, roubos e quebras operacionais. Segundo pesquisas realizadas pelo Instituto Brasileiro de Varejo e Mercado de Consumo (IBEVAR) e pelo Programa de Administração de Varejo (PROVAR), o índice apresentado é maior que o registrado globalmente $(1,36 \%)$ e maior que lugares como América do Norte $(1,49 \%)$, Europa $(1,27 \%)$ e América Latina (1,60\%). O segmento com maior representatividade nessas perdas são as pequenas e médias empresas com 4,44\%, seguido pelos supermercados com 2,98\%, as lojas de material de construção com $1,72 \%$ e as drogarias com 0,38\%. (ABRAS, 2015)

Com relação ao supermercado, segmento escolhido para esse estudo, 35,02\% das empresas não possuem uma área para prevenção de perdas. As suas principais causas são quebras operacionais com 33,35\%, erros de inventário (16,59\%), furtos externos $(16,03 \%)$ e internos $(8,64 \%)$. E os setores que apresentam maior índice de perdas são os de frutas, legumes e verduras (FLV) com 8,29\%, padaria e confeitaria (5,58\%), peixaria (4,35\%) e açougue (4,24\%). (ABRAS, 2015$)$.

São inúmeros os fatores que acarretam essas perdas e quebras, como o mau planejamento do setor de compras e vendas, seleção de fornecedores, danos no transporte e recebimento, forma de armazenagem, exposição do produto e manuseio impróprio.

Perante essas circunstâncias, surge a proposta de ações de melhorias visando minimizar as perdas aplicando o controle de qualidade no setor de hortifrúti de um supermercado. As perdas são recorrentes da diferença entre o estoque físico e contábil, ou seja, quando não é possível identificar a causa. As quebras são alimentos descaracterizados comercialmente, prazo de validade expirado ou consequência da má gestão dos produtos na empresa. É importante ressaltar que podem ocorrer dois tipos de quebras, os que são destinados ao lixo, alimentação animal e adubo por estar impróprio para o consumo humano e os que são considerados sobras, que não estão com boa aparência para serem vendidos, porém estão aptos para o consumo.

Para realizar o gerenciamento da empresa pelo controle de qualidade é imprescindível a utilização das sete ferramentas básicas da qualidade, sendo elas: as folhas de verificação, a estratificação, as cartas controle, os gráficos de dispersão, os diagramas de causa-efeito, os diagramas de Pareto e os histogramas. Para o emprego correto dessas ferramentas é usado a Metodologia de Análise e Solução de Problemas (MASP) que tem como base o ciclo Planejar, Executar, Verificar e Agir (PDCA).

Diante deste cenário, este artigo tem como objetivo principal aplicar as ferramentas da qualidade em busca de mensurar e minimizar as perdas ocorridas no setor de hortifrúti de uma rede de supermercados e propor uma metodologia para solução os problema de perdas deste setor.

\section{FERRAMENTAS DA QUALIDADE}

Para a implantação das metodologias, torna-se necessário a utilização de algumas das sete ferramentas da qualidade. Vieira $(2012$, p. 5) afirma que "As sete ferramentas estatísticas para o controle da qualidade são um conjunto de técnicas gráficas que permitem resolver boa parte dos problemas estatísticos que surgem no decorrer da análise de dados quando a intenção é manter a qualidade". Tais ferramentas são folha de verificação, histograma, fluxograma, diagrama de pareto, gráfico de dispersão, carta controle e diagrama de Ishikawa, sendo as mais significativas para o trabalho apresentadas a seguir. (SELEME; STADLER, 2010; VIEIRA, 2012; MENEZES, 2013).

- $\quad$ Folha de Verificação: é um documento em formato de tabela ou planilha para registrar anotações e dados, de forma organizada e norteada para o problema ou circunstâncias que se deseja resolver. Ela permite o registro de informações advindas de observações praticadas durante a execução dos processos. Esta ferramenta normalmente é a primeira a ser utilizada nas 
metodologias de solução de problemas. Proporciona coletas de dados rápidas e simples, economizando tempo e evitando anotações informais que são perdidas.

- Diagrama de Pareto: é um gráfico de barras desenvolvido para apresentar as causas de variação por ordem decrescente de frequência. Seu princípio é conhecido pela proporção "80/20", ou seja, a maior parte dos problemas procede de um número pequeno de causas, logo se estas forem identificadas e eliminadas, quase todos os problemas também serão.

- Diagrama de causa e efeito/Ishikawa: é uma representação gráfica que auxilia na identificação das causas que fazem com que o problema ocorra e põe em ordem as ideias sugeridas em categorias. Essas causas são caracterizadas pelo chamado 6Ms (método, mão de obra, materiais, máquina, meio ambiente e medição), que são denominadas causas primárias, pois delas provém a maior parte dos problemas.

- Diagrama de dispersão: é um gráfico que demonstra a relação entre duas variáveis. Pode ser utilizado para verificar a relação do problema com determinada causa estabelecida no diagrama de causa e efeito, confirmar a tese que duas variáveis são relacionadas e proporcionar o nível de força dessa relação.

Além das ferramentas básicas da qualidade, existem várias outras. Duas delas são o brainstorming e 5W2H, que auxiliam na solução de problemas. Segundo Seleme e Stadler (2010), o brainstormingé uma ferramenta empregada em reuniões onde os participantes tem autonomia para expor suas ideias, por mais improváveis que pareçam ser.

\section{METODOLOGIA}

Para desenvolver a pesquisa, foi adotado o estudo de caso utilizando a abordagem combinada ou quali-quantitativa. De forma a justificar esta escolha, a abordagem quantitativa foi aplicada na etapa de coleta de dados, onde foram coletadas por meio de folhas de verificação. Havendo a preocupação com a análise e quantificação das perdas, foi feita a coleta das variáveis que as influenciam, nos respectivos setores no qual o estudo se aplicará. Por meio da aplicação de gráficos de Pareto e gráfico de dispersão, os dados coletados foram analisados e verificados no que se refere à correlação entre as causas e o efeito por meio da abordagem estatística.

Os critérios de cunho qualitativo partiram de uma observação desenvolvida pela pesquisadora na organização, com o intuito de entender melhor o processo e em consulta de dados históricos, na busca de se realizar uma discussão comparativa referente às perdas existentes nos setores, desse modo possibilitando o melhor entendimento da natureza das variáveis a fim de desenvolver argumentos e propor soluções para a problemática.

\section{RESULTADOS}

A partir de observações e levantamentos, foi criada a folha de verificação que apresentou as perdas nos meses delimitados pelo estudo.

Com os dados coletados por esta ferramenta da qualidade, que são as folhas de verificação, foi possível uma análise por Pareto trimestral no período de 2015 e 2016, esta análise resultou nas seguintes observações pelas autoras da pesquisa.

O primeiro trimestre de 2015 apresentou um total de quebra de $19.548,740 \mathrm{Kg}$, representando $6,35 \%$ das vendas do setor nesse trimestre.Os itens que compõe os $80 \%$ de quebra respectivamente são: laranja, tomate rasteiro, batata extra, mamão formosa, limão, maça gala, mamão papaia, maça fuji, abacaxi hawai, banana maça, cebola, berinjela, banana prata, manga, goiaba, melancia, cenoura, repolho, chuchu, laranja lima e pêssego, representando frutas, legumes e tubérculos.

Em contrapartida, o primeiro trimestre de 2016 teve um total de quebra de $13.888,559 \mathrm{Kg}$, representando $5,33 \%$ das vendas do setor no respectivo trimestre. Os produtos que representam $80 \%$ das quebras na devida ordem são: tomate rasteiro, laranja, batata extra, cebola, banana 
nanica, mamão papaia, mamão formosa, melancia, banana prata, pêssego, laranja lima, limão, banana maça, manga, repolho, maça fuji, abacaxi hawai, cenoura, goiaba, maça gala, pera

No segundo trimestre de 2015 obteve-se um total de quebra de 15.637,390Kg, representando $5,21 \%$ das vendas do setor nesse trimestre. Os itens que compõe os $80 \%$ de quebra respectivamente são: poncan, mamão formosa, laranja, batata extra, maça gala, mamão papaia, melancia, tomate rasteiro, cebola, maça fuji, limão, abacaxi hawai, caqui, berinjela, pera argentina.

No mesmo período do ano 2016 , o setor apresentou um total de quebra de $12.278,648 \mathrm{Kg}$, representando $5,11 \%$ das vendas do hortifrúti nesse trimestre. Os itens banana nanica, tomate rasteiro, poncan, batata extra, laranja, cebola, mamão formosa, abacaxi hawai, repolho, berinjela, maça gala, goiaba, pepino japonês, melancia, limão, cenoura, banana prata, pera, argentina willians, banana maça, maça fuji, caqui e abobora menina, representaram $80 \%$ das quebras.

Foi realizado um brainstorming com alguns funcionários do supermercado. A equipe que compôs esta atividade foi formada por pessoas que são peças chave no processo de gerenciamento de compras e operações. O efeito principal do brainstorming foi constatar as possíveis causas que acarretavam as perdas de cada um desses produtos.

Com o intuito de entender e expor tudo que foi levantado, utilizou-se a ferramenta diagrama de causa e efeito para organizar as origens das perdas de acordo com suas respectivas categorias. Uma vez que a mesma possibilita que o grupo mantenha-se focado nas causas e não mais nos efeitos.

Figura 1. Diagrama de Ishikawa para determinação das causas primárias.

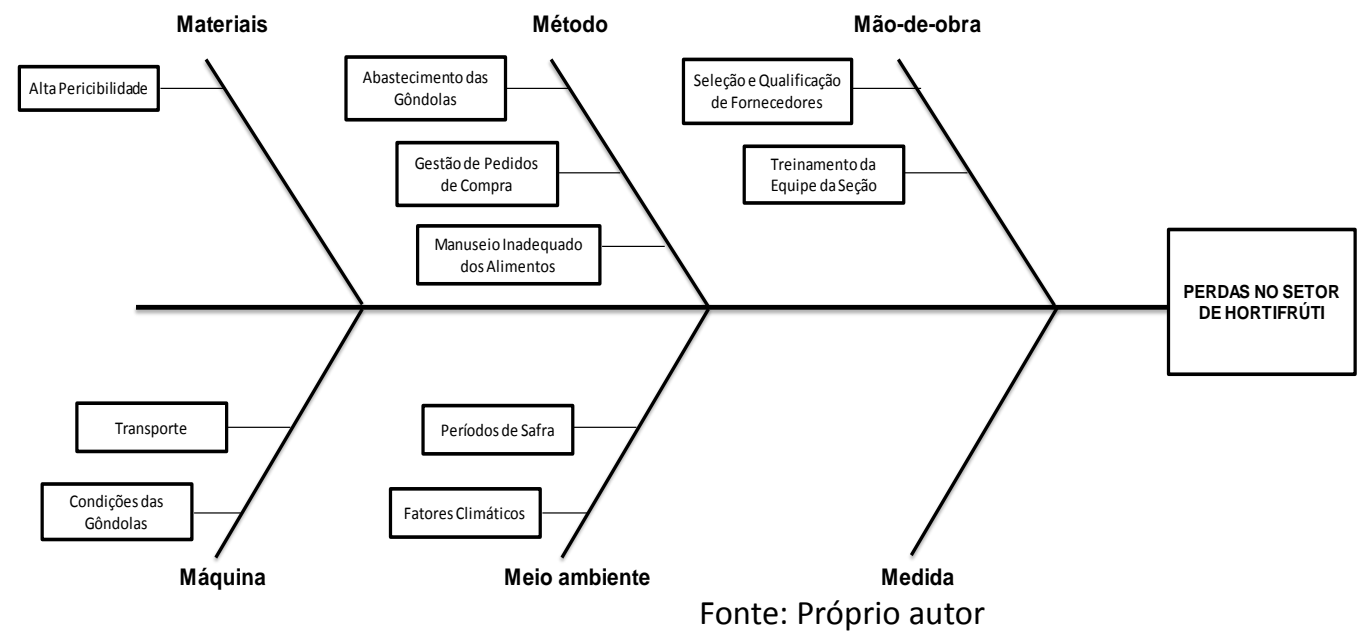

Com o desenvolvimento da previsão de vendas, pretende-se estabelecer a quantidade de $\mathrm{Kg}$ e/ou unidade necessário para atender de forma satisfatória os clientes e diminuir as perdas ocasionadas pelos pedidos maiores de compra em época de safra, como demonstra a Figura 2, representação gráfica para demanda diária do produto laranja. 
Figura 2. Demanda diária da laranja.

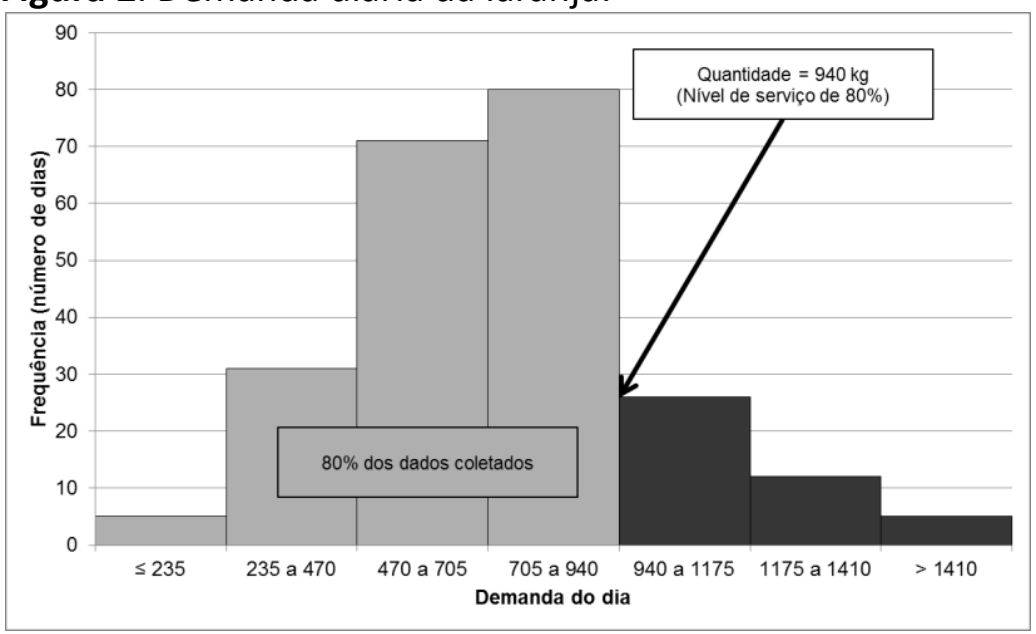

Fonte: Próprio autor

\section{DISCUSSÃO}

Em resumo, os fatores que provocam ou auxiliam o aumento das quebras são o excesso de umidade relativa do ar, alta atividade de água característica do próprio alimento e oscilações na temperatura provocada pelas alterações climáticas devidas estações chuvosas e secas. Quando se trata de perdas ocasionadas pela ação do homem, estão relacionados o transporte em grandes distâncias, manuseio incorreto ou excessivo e acondicionamento não adequado, onde favorecem as ações do escurecimento enzimático devido a atuação das enzimas oxidantes.

No que se refere às práticas de controle de qualidade, o presente trabalho tem como proposta a implantação de procedimentos operacionais padronizados e avaliação de fornecedores a fim de eliminar ou minimizar as perdas do setor de hortifrúti do supermercado. A criação destes procedimentos irão orientar as sequências das atividades e a periodicidade de realização. Por meio dessa padronização, busca-se diminuir a incidência de desvios na realização das tarefas.

De forma indireta o procedimento operacional padrão também atuará sobre a perecibilidade dos alimentos e as condições das gôndolas, pois nele também estará discriminada a forma e a frequência de higienização. O processo de higienização apropriado é importante para diminuir as condições favoráveis para o desenvolvimento de microrganismos e evitar a deterioração e/ou contaminações nestes alimentos, esse processo deve ser realizado em um determinado intervalo de tempo, utilizando produtos químicos que tem por função limpar as superfícies e sanitizá-las.

O intuito da proposta de avaliação de fornecedores é diminuir ou eliminar as perdas/quebras derivadas da aquisição do produto, esta avaliação de fornecedores deverá ser feita por meio de um formulário, com atribuições de nota a cada requisito estabelecido pela empresa, os requisitos são condições básicas que devem ser atendidas pelo fornecedor para que ele esteja apto a fornecer seus produtos à referida empresa. A avaliação das entregas deverá ser feita periodicamente e registrado a sua conformidade de acordo com os requisitos exigidos pela empresa, a fim de analisar o desempenho individual de cada fornecedor e assim fazer uma triagem e ter subsídios para escolher aqueles que mais se adequam as exigências da empresa, é imprescindível que o fornecedor entenda seu papel e se adeque a padrão de qualidade necessitado pela empresa.

Através do histórico de vendas da laranja do primeiro semestre de 2015 e 2016, desenvolveu-se o gráfico de demanda do dia x frequência (FIGURA 2). Ele expressa a quantidade de dias em que determinada demanda diária apresentou-se dentro do período estudado. Assim, a quantidade de laranja necessária para atender um nível de serviço de $80 \%$ é de $940 \mathrm{Kg}$ diários. 
Assim como para a laranja, foi feito uma previsão diária para todos os outros produtos que se enquadram dentro do nível de serviço de $80 \%$.

\section{CONCLUSÃO}

Com a aplicação das ferramentas da qualidade a fim de diagnosticar as origens do problema. Constatou-se que no primeiro trimestre de 2015 o setor teve uma quebra de 6,35\% referente às vendas, no primeiro trimestre de 2016 teve 5,33\%, no segundo trimestre de 2015 foi de $5,21 \%$ e no segundo trimestre de 2016 foi de 5,11\%. Foi possível identificar os fatores que provocam ou auxiliam o aumento das quebras no setor de hortifrúti são: a alta perecibilidade dos alimentos, o método de abastecimento das gôndolas, a gestão de pedidos de compra, os manuseios inadequados dos alimentos, a seleção e qualificação dos fornecedores, o treinamento da equipe da seção, o transporte, a condição das gôndolas, os períodos de safra e os fatores climáticos.

Com a previsão de vendas obteve-se uma quantidade de pedido diário de 150 und de abacaxi hawai, $100 \mathrm{Kg}$ de abobora menina, $85 \mathrm{Kg}$ de banana maça, $450 \mathrm{Kg}$ de banana nanica, $80 \mathrm{Kg}$ de banana prata, $480 \mathrm{Kg}$ de batata extra, $134 \mathrm{Kg}$ de berinjela, $322 \mathrm{Kg}$ de caqui, $380 \mathrm{Kg}$ de cebola, $240 \mathrm{Kg}$ de cenoura, $132 \mathrm{Kg}$ de chuchu, $140 \mathrm{Kg}$ de goiaba, $940 \mathrm{Kg}$ de laranja, $72 \mathrm{Kg}$ de laranja lima, $250 \mathrm{Kg}$ de limão, $144 \mathrm{Kg}$ de maça fuji, $180 \mathrm{Kg}$ de maça gala, $252 \mathrm{Kg}$ de mamão formosa, $100 \mathrm{Kg}$ de mamão papaia, $60 \mathrm{Kg}$ de manga, $264 \mathrm{Kg}$ de melancia, $132 \mathrm{Kg}$ de pepino japonês, $114 \mathrm{Kg}$ de pera argentina willians, $201 \mathrm{Kg}$ de pêssego, $584 \mathrm{Kg}$ de poncan, $200 \mathrm{Kg}$ de repolho e $660 \mathrm{Kg}$ de tomate rasteiro.

\section{REFERÊNCIAS}

ASSOCIAÇÃO BRASILEIRA DE SUPERMERCADOS.Varejistas perdem 2,89\% da receita em ineficiências e roubos. 2015. Disponível em:

<http://www.abras.com.br/clipping.php?area=1\&clipping=53771>. Acesso em: 30 mar. 2016.

GOZZI, M. P. Gestão da Qualidade em Bens e Serviços. 2. ed. São Paulo: Person Education do Brasil, 2015. Disponível em:

<http://unoeste.bv3.digitalpages.com.br/users/publications/9788543010175/pages/-12>. Acesso em: 18 abr. 2016.

MELLO, C. H. P. Gestão da qualidade. São Paulo: Person Education do Brasil, 2011. Disponível em: <http://unoeste.bv3.digitalpages.com.br/users/publications/9788576056997/pages/_1>. Acesso em: 15 abr. 2016.

MENEZES, F. M. MASP Metodologia de Análise e Solução de Problemas. Porto Alegre: ABDI, 2013.

SELEME, R.; STADLER, H. Controle da Qualidade: as ferramentas essenciais. 2. ed. Curitiba: Ibpex, 2010.

VIEIRA, S. Estatística para a qualidade. 2. ed. Rio de Janeiro: Elsevier, 2012. 